\title{
ANÁLISE DOS CONFLITOS DO USO E OCUPAÇÃO DO SOLO EM ÁREA DE PRESERVAÇÃO PERMANENTE - APP - URBANA
}

\author{
Isabella Aragão Araújo
}

\begin{abstract}
RESUMO
O estudo visa identificar os conflitos existentes em relação ao uso e ocupação do solo, em relação às Áreas de Preservação Permanente - APP - em área urbana, através de um estudo de caso da área de APP em torno do córrego do Jardim Padroeira, Osasco, SP, localizado na área metropolitana de São Paulo. A análise permitiu observar que a área vem sofrendo alterações ao longo das décadas, mas que a função de preservação permanente da vegetação ainda não está sendo cumprida. Conclui-se que apesar das legislações vigentes no ordenamento territorial, ainda é difícil a aplicação dos mesmos em áreas de preservação permanente urbana. Palavras-chaves: meio ambiente urbano; área de proteção permanente em área urbana; sustentabilidade urbana.
\end{abstract}

\begin{abstract}
The study aims to identify the existing conflicts regarding land use and occupation, in relation to the Permanent Preservation Areas - APP - in urban area, through a case study of the APP area around the Jardim Padroeira stream, Osasco, SP, located in the metropolitan area of São Paulo. The analysis showed that the area has undergone alterations throughout the decades, but that the function of permanent preservation of the vegetation is still not being fulfilled. It is concluded that in spite of the legislation in force in the territorial planning, it is still difficult to apply them in areas of permanent urban preservation.
\end{abstract}

Keywords: urban environment; Permanent protection area in urban area; Urban sustainability. 


\section{Introdução}

Nas últimas décadas, houve um aumento na preocupação mundial em relação ao meio ambiente e as populações urbanas. No Brasil, o início da preocupação ambientalista restringia-se aos recursos naturais, mas com o crescimento demográfico e a migração campocidade ocorrida nos anos 80 , fez com que se agravassem os problemas urbanos. As cidades começam a ter prolongamentos urbanos, zonas periféricas, em regras gerais ocupadas por populações carentes que se veem obrigadas a abandonar a vida campesina em razão da mecanização da agricultura (FREITAS, 2016). A intensificação do processo de urbanização relacionou diretamente as várzeas com o local destinado para as populações de baixa renda, associadas à exclusão social, enchentes, doenças ocasionadas pela proximidade das águas poluídas (LUCAS, 2008). Visando a preservação da vegetação e dos recursos hídricos, a áreas de preservação permanente - APP - é um instituto jurídico que busca proteger:

"áreas com a função ambiental de preservar recursos hídricos, a paisagem, a estabilidade geológica, a biodiversidade, o fluxo gênico de fauna e flora, proteger o solo e assegurar o bem-estar das populações humanas" (BRASIL, 2012).

Com o novo Código Florestal de 2012 impondo critérios e restrições ao uso e ocupação do solo em zonas urbanas, surgiram conflitos com as normas urbanísticas existentes, e para Azevedo e Oliveira "muitos aglomerados urbanos foram se expandindo em conformidade com as normas urbanísticas, porém em conflito com o Código Florestal e as demais normas relativas às APPs" (AZEVEDO, OLIVEIRA, 2014, p.75). Esse texto busca uma reflexão sobre os temas relacionados às áreas de preservação permanente em zona urbana, e seus conflitos de uso e ocupação do solo. Além também de realizar um estudo de caso na área de preservação permanente do Córrego do Jardim Padroeira em Osasco - SP, sob a ótica do Código Florestal.

Esse estudo será organizado em três partes. A primeira parte visa realizar uma análise comparativa a legislação vigente sobre as áreas de preservação permanente, buscando identificar similaridades e conflitos com a regulação urbanística. A segunda parte realizará um estudo de caso no Córrego do Jardim Padroeiro em Osasco - SP, utilizando instrumentos e softwares gratuitos de geotecnologia como Google Earth, para realizar o levantamento dos conflitos de uso e ocupação do solo na área de preservação permanente urbana estudada. A terceira parte será uma discussão sobre como os conflitos identificados interferem na vida dos indivíduos estudados e como isso afeta o meio ambiente em meio urbano.

Inicialmente o artigo inicia-se discutindo o conteúdo normativo envolvendo o código florestal e a legislação vigente nas áreas urbanas, procurando identificar concordância e 
contradições entre a gestão urbana e a gestão ambiental. Posteriormente, o texto analisará os conflitos que as normas legislativas podem causar em uma área de estudo localizada no município de Osasco. Por fim, através dos dados coletados no estudo de caso, será realizada uma reflexão sobre os conflitos identificados em relação ao planejamento urbano-ambiental brasileiro.

\section{Materiais e métodos}

Primeiramente, para execução desse artigo, será realizada uma reflexão sobre o Código Florestal, as normas urbanísticas, e outras regulamentações que sejam relevantes sobre o tema Área de Preservação Permanente. Além disso, será realizado um estudo de campo sobre aspectos físicos e sociais do Córrego do Jardim Padroeira em Osasco, visando realizar representações gráficas através de softwares gratuitos sobre os dados coletados no estudo de caso. O mapeamento da área de estudo será realizado por softwares gratuitos (Google Earth), pois possui livre licença, tornando assim um método acessível para qualquer estudo geográfico.

\section{Área de preservação permanente}

\section{Origem do conceito e sua definição legal}

O Código Florestal Brasileiro de 1965 instituiu o conceito legal de Área de Preservação Permanente. Segundo Ribeiro (2011), a redação do Código Florestal de 1965 é possível observar que a definição de florestas protetora mostra um nítido sentido preservacionista ecossistêmico. Em relação ao Novo Código Florestal de 2012, instituído pela Lei 12.651/2012, Machado diz que dois fundamentos da lei merecem ser apontados "proteção e uso sustentável das florestas e demais formas de vegetação nativa em harmonia com a promoção do desenvolvimento econômico" e a afirmação de que "as florestas são bens de interesse comum a todos os habitantes do País" (MACHADO, 2013, p.866).

Para Talden,

as Áreas de Preservação Permanente - APPs são localizações definidas pelo Código Florestal ou por regulamento específico onde a rigor não são permitidas as alterações antrópicas, ou seja, as interferências do homem sobre o meio ambiente, a exemplo de um desmatamento ou de uma construção. (TALDEN, 2015, p.180) 
Existem dois tipos de Área de Preservação Permanente: as legais, que são áreas previstas pelo Código Florestal; e as administrativas, que são áreas criadas por ato do Poder Público municipal, estadual ou federal. Machado (2013) diz ser possível classificar as Áreas de Preservação Permanente em três grandes categorias: a primeira, como protetora das águas (APPs de nascentes, cursos d'água e reservatórios); a segunda, como protetora de montanhas (APPs de topo de morro, encostas); e a terceira, como protetora de ecossistemas determinados (APPs de manguezais, veredas).

Azevedo e Oliveira (2013) dizem que em tese, as APPs são estabelecidas para proteção total e definitiva da utilização estritamente econômicas, pois estas áreas são caracterizadas pela intocabilidade e vedação de uso econômico direto. No entanto, a legislação permite exploração em caso de utilidade pública e de interesse social, além também de casos de utilização de menor impacto ambiental destas áreas.

\section{Área de Preservação Permanente Urbana}

A relação entre APPs e zonas urbanas nunca foi harmoniosa. Azevedo e Oliveira (2013) afirmam que isso deve-se ao fato de que o Código Florestal de 1965 não tutelava as zonas urbanas, focava apenas em áreas rurais. Portanto, não era objetivo do Código Florestal impor critérios e restrições ao uso e ocupação do solo urbano. Porém, com a aprovação do novo Código Florestal em 2012, as APPs em zonas urbanas também foram estabelecidas pela nova legislação.

Umas das inovações que o Código Florestal de 2012 trouxe em relação às intervenções em Áreas de Preservação Permanente em zona urbana, segundo Azevedo Oliveira (2013), foram:

(1) obras de infraestrutura destinadas ao sistema viário, inclusive aquele necessário aos parcelamentos de solo urbano, aprovado pelos Municípios; e (2) instalações necessárias à realização de competições esportivas estaduais, nacionais ou internacionais. (OLIVEIRA, 2013, p.81)

Estas inovações podem abrir precedentes perigosos em intervenções em Áreas de Preservação Permanente urbana intactas.

Almeida (2011) diz os instrumentos de ordenamento territorial podem ser divididos em quatro categorias: 1) os normativos (incluem a legislação sobre uso e ocupação do solo; Código Florestal); 2) os de fiscalização e controle das atividades; 3) os preventivos (caracterizados pela delimitação de espaços territoriais protegidos, por exemplo, as APPs); e 4) os corretivos (intervenções na infraestrutura e no meio ambiente). Apesar de ser um 
instrumento normativo para a gestão territorial, Machado (2014) afirma a aplicabilidade do Código Florestal em áreas urbanas ainda é uma questão que levanta muitos questionamentos, não havendo um consenso, em especial a aplicabilidade do Código Florestal na área urbana consolidada e áreas de ocupação mais antiga.

\section{ESTUDO DE CASO - Córrego Jardim Padroeira - Osasco,SP.}

O município da área de estudo é o de Osasco, localizado na Região Metropolitana de São Paulo, com uma extensão territorial de 64,954km² e uma população (Censo, 2010) de 666.740 habitantes. Com uma extensão territorial dentre as menores do estado de São Paulo e com a sexta maior população do estado (CENSO, 2010), faz com que a densidade demográfica seja de 10.264,80 hab/km² . O PIB per capita municipal (2013) é de 80.265,37 reais e o rendimento médio per capita (2010) é de 1114,77 reais.

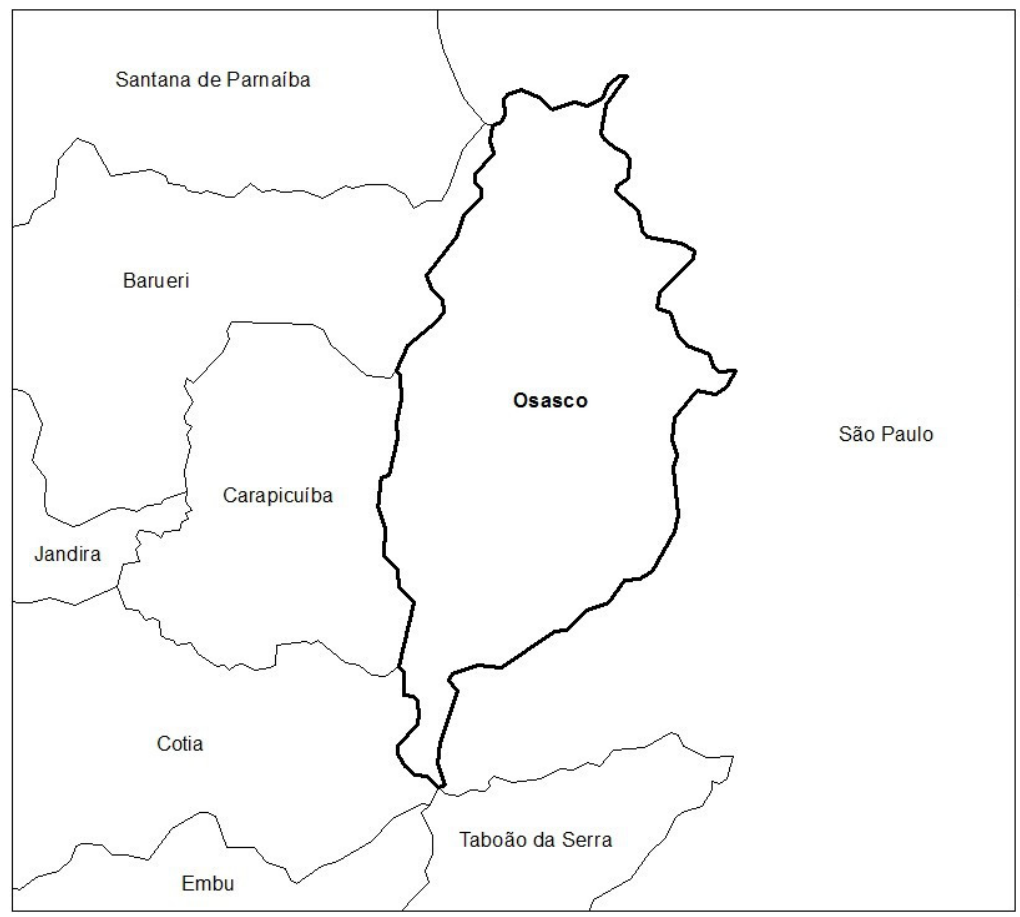

Figura 1 - Localização do município de Osasco na Região Metropolitana de São Paulo. Fonte: PMO.

A área de estudo localiza-se no Jardim Padroeira, zona sul do município de Osasco, SP. A área apresenta uma vulnerabilidade econômica alta e muito alta (PMO, 2010), com uma população com rendimento mensal de 2 a 3 salários-mínimos (IBGE, 2010) e densidade demográfica de 50 mil habitantes por $\mathrm{km}^{2}$. Há presença de assentamentos irregulares, e segundo Maricato (2013), a maior parte das moradias, assim como boa parte das cidades construídas no país nos últimos vinte anos, foram construídas sem financiamento, sem conhecimento técnico e fora da lei. 
Observa-se por imagens de satélite que a área vem sofrendo com intervenções antrópicas há anos. Em 2002 a área possuía uma significativa densidade demográfica em apenas uma das margens do córrego, com edificações e habitações de um lado da margem e um campo aberto sem vegetação do outro lado da margem. Em 2008, a área que até então não era utilizada de um dos lados do curso d'água, passou a apresentar uma maior ocupação de assentamentos irregulares. O destaque é que neste ano não se encontram apenas assentamentos irregulares na área, há também um condomínio residencial próximo ao córrego. No ano de 2013, parte da população foi removida de uma das margens do córrego. Em 2016, é verificado que parte da vegetação nativa retornou para a área de estudo, mas as ocupações continuam densas, prejudicando assim a preservação do curso d'água.

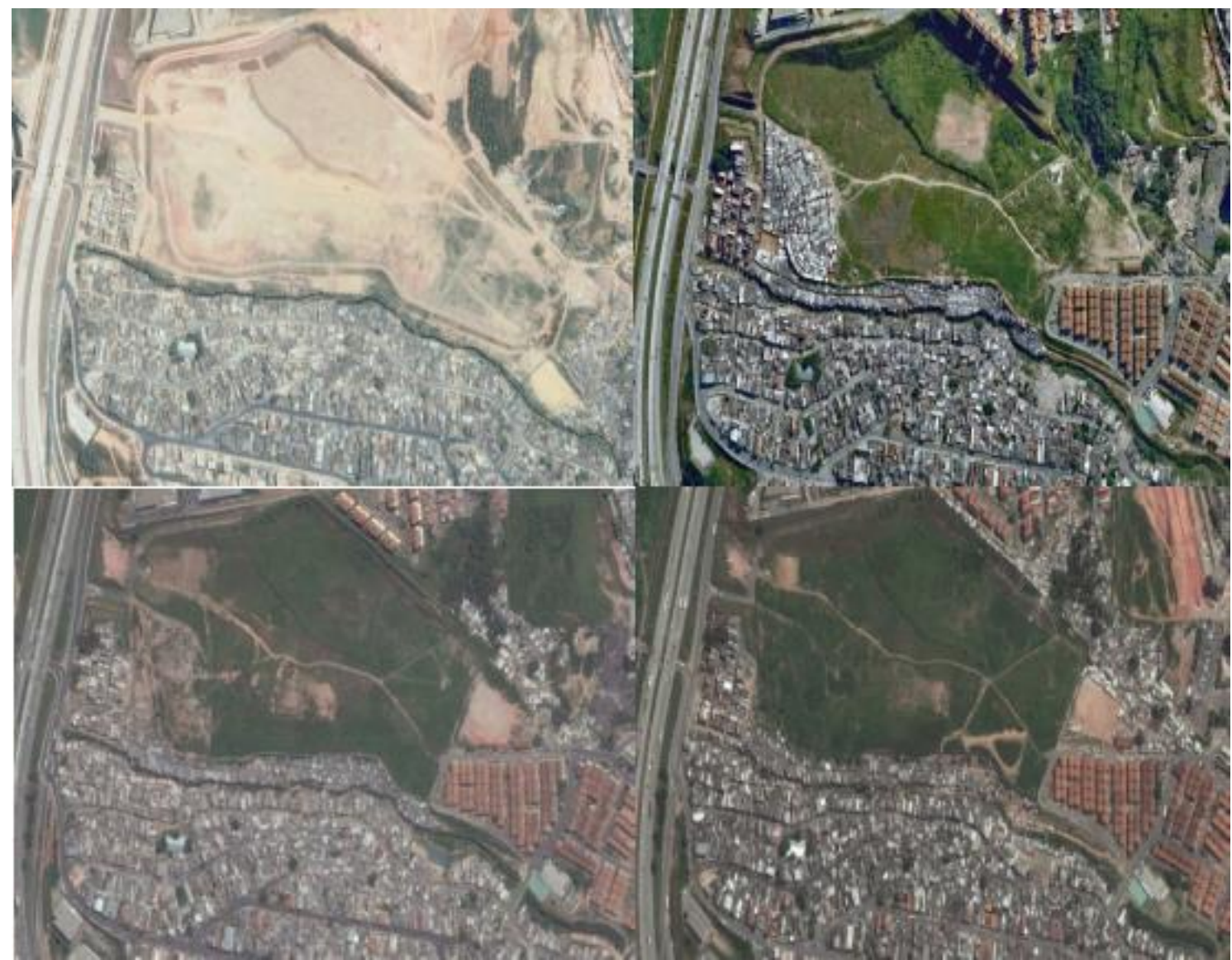

Figura 2 - Imagens de satélite da evolução do Uso e Ocupação do Solo na Área de Estudo. Superior direita: ano de 2002; superior esquerda: ano de 2008; inferior direita: ano de 2013; inferior esquerda: ano de 2016. Fonte: GoogleEarth. 


\section{Resultados obtidos}

O córrego localiza-se na divisa com o município de Carapicuíba, próximo ao trecho oeste do Rodoanel. Ele é afluente do Ribeirão Carapicuíba, fazendo parte da Bacia Hidrográfica do Tietê. Dois tipos de Área de Preservação Permanente foram encontrados na presente área de estudo foram: a APP de nascente e a APP de curso d'água, esta última possui um curso de aproximadamente 900 metros de extensão e largura do seu curso d'água é inferior a 50 metros e superior à 10 metros (aproximadamente 15 metros de largura).

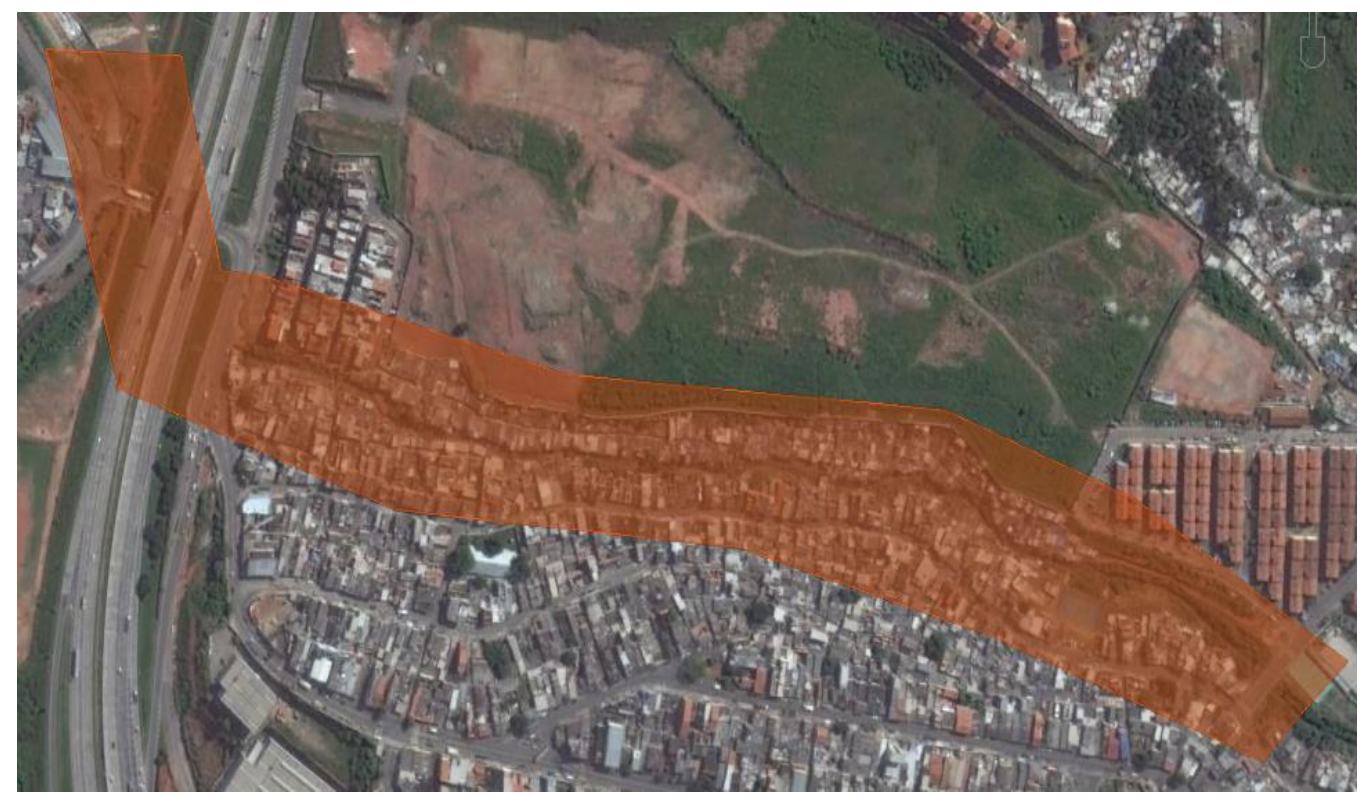

Figura 3 - Área de Estudo do Jardim Padroeira, Osasco, SP. A área de Preservação Permanente é delimitada pelo polígono alaranjado. Fonte: GoogleEarth (2017).

O principal conflito de uso é o de habitação, principalmente de assentamentos irregulares de alta densidade demográfica (Figura 4). Há presença também do Rodoanel na área de estudo, mas segundo o Código Florestal, o município pode autorizar intervenções que influenciam no sistema viário local. Nota-se que devido a alta densidade demográfica presente na área, as atividades de habitação neste caso não são de baixo impacto ambiental, já que impactos como esgotamento a céu aberto e resíduos sólidos com destinação incorreta. 


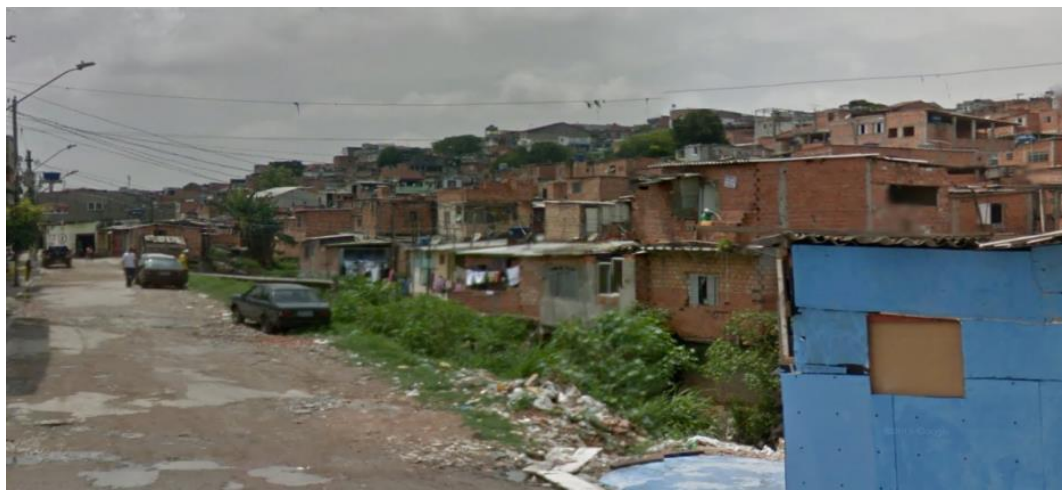

Figura 4 - Assentamentos irregulares identificados na área de estudo. Fonte: GoogleStreet.

Há presença de Zonas Especiais de Interesse Social 2 e 3 na área de estudo. Segundo

Lei Complementar 152/06 asZEIS 2 são favelas, cortiços, assentamentos informais, urbanizados ou em processo de urbanização, situados em áreas públicas ou particulares; e as ZEIS 3 são loteamentos de interesse social, loteamentos irregulares ou clandestinos, urbanizados ou em processo de urbanização situados em áreas publicas e particulares, comprovadamente ocupados até junho de 2005. Apesar de possuírem classificações pela lei municipal, detalhes de regularização fundiária ou de instrumentos utilizados para o cumprimento da função social da propriedade ainda permanecem obscuros juridicamente. Dependendo da interpretação, a função de preservar o meio ambiente fica em risco, sendo sobreposta pela função de moradia de interesse social.

Utilizando o instrumento urbanístico da Lei de Uso e Ocupação do Solo do município de Osasco (OSASCO, 1978), foi possível identificar que a área de estudo localiza-se em uma zona de uso predominantemente residencial. É importante ressaltar que área é próxima a zonas industriais e zonas consideradas áreas verdes, e a principal contradição é que o Rodoanel está localizado em zona de área verde. Observa-se então uma tendência do município em destinar a área para uso residencial do que para uso ambiental. 


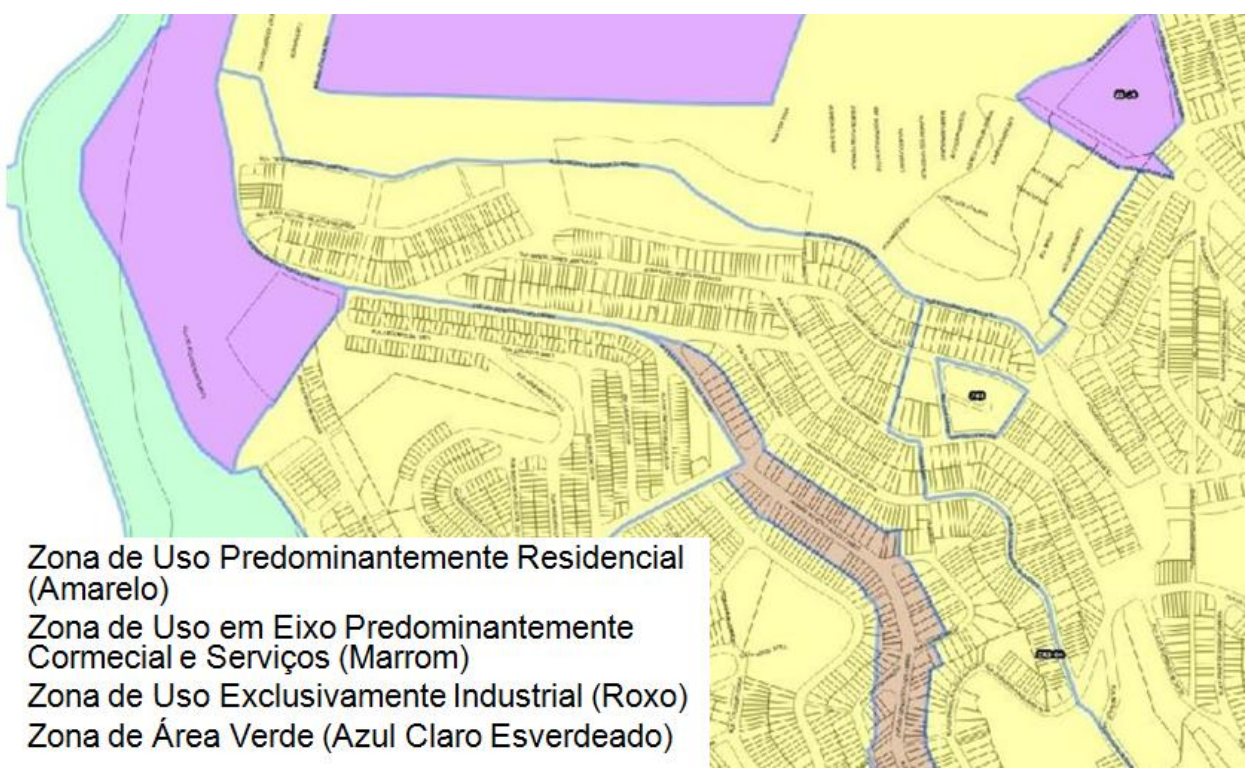

Figura 5 - Zoneamento presente na área de estudo. Fonte: Prefeitura Municipal de Osasco.

\section{Conclusão}

O Código Florestal trouxe um conteúdo normativo muito importante para a gestão do território, porém, seu conteúdo ainda é conflitante na gestão urbana, principalmente pelo fato de como uma lei federal pode interferir na disciplina de uso e ocupação do solo, sendo que essa disciplina é responsabilidade do município. As leis municipais de uso e ocupação do solo são encarregadas pela gestão do território, porém ainda há muita dificuldade em determinar as áreas de preservação permanente nos mesmos, principalmente pela motivação econômica.

Apesar da preocupação com o meio ambiente, as áreas de preservação permanente em área urbana ainda apresenta desafios como moradia e atividades de alto impacto ambiental. A insegurança jurídica é o principal desafio a ser superado pela gestão territorial, e combinar os conteúdos normativos com os instrumentos de gestão ambiental e gestão urbana são extremamente importantes para garantir a qualidade de vida de todos no futuro. 


\section{Referências bibliográficas}

ALMEIDA, Flávio Gomes de. In: Território, Territórios: ensaios sobre o ordenamento territorial. O ordenamento territorial e a geografia física no processo de gestão ambiental. $3^{\text {a }}$ Edição. Editora Lamparina. Rio de Janeiro, 2011.

AZEVEDO, Emmanuel Silva; OLIVEIRA, Vládia Pinto Vidal. Reflexos do Novo Código Florestal nas Áreas de Preservação Permanente - APPs - urbanas. Universidade Federal do Paraná. Desenvolvimento e Meio Ambiente, v 29, p 71-91, abril, 2014.

FARIAS, Talden. COUTINHO, Francisco Seráphico da Nóbrega. Melo, Geórgia Karênia R.M.M. Direito Ambiental. $3^{\text {a }}$ Edição. Editora JusPODIVM. Salvador, 2015.

FREITAS, Vladimir Passos. Análise das Complexas Relações entre Pobreza e Meio Ambiente Urbano no Brasil. Unisul de Fato e Direito, ano XVII - n 12, janeiro de 2016.

GUIMARÃES, Bruno Bianchi; GUIMARÃES, Raul Borges; LEAL, Antonio Cezar. Código Florestal Brasileiro: análise do conceito de Área de Preservação Permanente e sua aplicação na bacia hidrográfica do Córrego São Pedro - Anhumas, São Paulo. Boletim Campineiro de Geografia, v. 5, n 1, 2015.

LABHAB - LABORATÓRIO DE HABITAÇÃO E ASSENTAMENTOS HUMANOS DA FACULDADE DE ARQUITETURA E URBANISMO DA UNIVERSIDADE DE SÃO PAULO (São Paulo). Universidade de São Paulo. Impactos urbanísticos do Trecho Oeste do Rodoanel Mario Covas. 2005. p. 93-94.

LUCAS, Renata Paula. O Código Florestal em Meio Urbano: Implicações da aplicação da Lei $n^{0}$ 7.803/89 na regularização de assentamentos irregulares em grandes cidades. Dissertação (Mestrado - Programa de Pós-Graduação em Arquitetura e Urbanismo. Área de Concentração: habitat) - Faculdade de Arquitetura e Urbanismo da Universidade de São Paulo, São Paulo, 2008.

MACHADO, Paulo Affonso Leme. Direito Ambiental Brasileiro. $21^{\mathrm{a}}$ Edição. Malheiros Editores Ltda. São Paulo, 2013.

MARICATO, Ermínia. Brasil, cidades: alternativas para a crise urbana. $7^{\text {a }}$ Edição. Editora Vozes. Petrópolis, 2013.

OSASCO (Município). Lei Ordinária n ${ }^{\circ}$ 1485, de 12 de outubro de 1978. Estabelece Os Objetivos e As Diretrizes Para Uso e Ocupação do Solo Urbano no Município de Osasco. Seção 2, p. 1. 